\title{
POSSIBILITIES OF REDUCTION OF GROWTH OF INTERMETALLIC INTERLAYER IN STEEL BRAZED USING BRAZING FILLER METALS OF COPPER-PHOSPHORUS SYSTEM
}

\author{
A.N. PISAREV, V.F. KHORUNOV, S.M. MAKSYMOVA and V.N. TOVMACHENKO \\ E.O. Paton Electric Welding Institute, NASU \\ 11 Kazimir Malevich Str., 03680, Kiev, Ukraine. E-mail: office@paton.kiev.ua
}

\begin{abstract}
Brazed joints are widely used in development of structures in the different branches of industry. Their service properties depend on safety of the brazed joints. One of the reasons of low properties of the brazed structures is formation of the solid continuous interlayers of brittle intermetallic compounds along seam-brazed metal interface. This work studies some dependencies of formation of iron phosphides in steel brazing using $\mathrm{Cu}-\mathrm{P}$ filler metals. Using the reference data and thermodynamic calculations it was an attempt to reduce their growth and rate of formation by means of manganese, titanium and nickel alloying. Interaction of metal being brazed with brazing filler metal can provoke two mutually antithetic processes at the interface, namely dissolving the solid metal in the liquid, and diffusion of atoms of the liquid metal in the solid one with formation of chemical compounds. Investigation of phase and chemical composition of interaction zone showed that it consists of a Cu-based solid solution and $\mathrm{Fe}_{2} \mathrm{P}$ and $\mathrm{FeP}$ phosphides, forming at the interface in form of continuous interlayer. Thermodynamic possibility of phosphide formation is verified by calculation of Gibbs thermodynamic potential of corresponding reactions. Study of phase equilibriums and mutual solubility of components and compounds of $\mathrm{Fe}_{2} \mathrm{P}-\mathrm{Cu}_{3} \mathrm{P}-\mathrm{Ni}$ section of tetradic system $\mathrm{Fe}-\mathrm{Ni}-\mathrm{Cu}-\mathrm{P}$ showed that nickel and its phosphides can form the continuous solid solutions with iron as well as copper. Similarity of the crystal lattices of copper solution and iron phosphide and their parameters indicate that introduction of nickel to $\mathrm{Cu}-\mathrm{P}$ brazing filler metal will provide their solving in a brazed seam. 11 Ref., 3 Figures.
\end{abstract}

Keywords : brazing, Cu-P brazing filler metal, intermetallics' solubility, thermodynamic calculations, diffusion, phosphides, $X$-ray pattern, phase

Brazing of the most structural materials and, in particular, of steels using $\mathrm{Cu}-\mathrm{P}$ BFMs does not provide sufficiently strong joint. However, taking into account that alloys of this system are cheap and domestically manufactured in a wide range, the industry is interested in development of the Cu-P BFM suitable for steel brazing [1, 2].

The main difficulty lies in the fact that these BFMs currently can not be used in brazing of Fe-based alloys, from which the most part of brazed components are made, due to formation of comparatively wide brittle interlayers of iron phosphides [1] at the seambrazed metal interface. Taking into account that presence of the intermetallic interlayer in a seam zone can be a reason of joint fracture, it was an attempt to set some dependencies of phosphides formation and possibility of reduction of their growth in steel brazing using $\mathrm{Cu}-\mathrm{P}$ BFMs.

30 alloys were melted for the experiments. The initial material for samples production were powders containing, wt.\%: Fe (0.9999), Ni (0.9998), Cu (0.9999) and red phosphorus (0.9999). $\mathrm{Fe}_{2} \mathrm{P}$ and $\mathrm{Cu}_{3} \mathrm{P}$ phosphides were preliminary produced by means of sintering a pressed charge in a quartz vessel at 1170 $1220 \mathrm{~K}$ during $24 \mathrm{~h}$. Then, produced phosphides and nickel were fused in an electric-arc furnace on copper water-cooled hearth using argon atmosphere; specimens' compositions were controlled by weighing (deviation of specimen mass from charge mass did not exceed $2 \%$ ). Homogenizing annealing was carried out at $870 \mathrm{~K}$ in the pumped quarts vessels during $1000 \mathrm{~h}$ and then they were quenched. The quartz vessels were gradually cooled from $870 \mathrm{~K}$ to room temperature during $200 \mathrm{~h}$ in order to study phase composition of the specimens at room temperature.

$\mathrm{X}$-ray phase analysis was carried out by means of comparison with known X-ray patterns of pure elements and compounds. The X-ray patterns were made in Debay cylindrical camera $(d=57.3 \mathrm{~mm})$ in chromium radiation with asymmetric film positioning.

Review of references [3, 4] and direct experiments, based on investigation of structure of the steel brazed joints, produced using $\mathrm{Cu}-\mathrm{P}$ BFMs, allowed determining that the solid intermetallic interlayer is formed in the seam in the case when solubility of elements of BFM and metal being brazed in each other is 


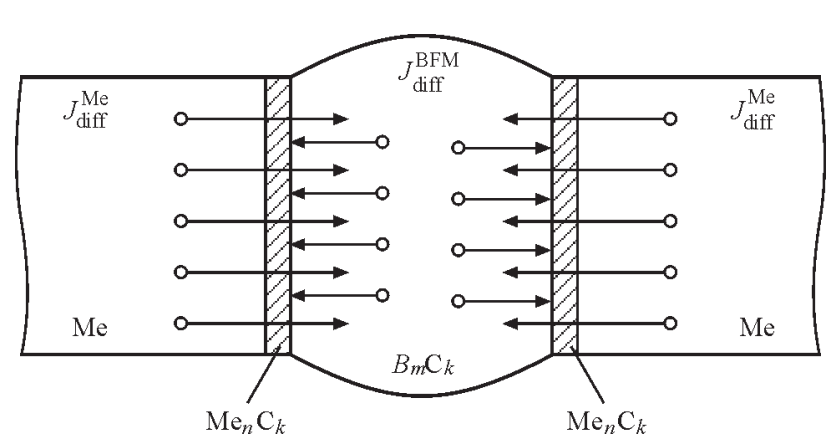

Figure 1. Scheme of mutual diffusion of solid brazed metal and liquid BFM: $J_{\text {diff }}^{\mathrm{Me}}$ - diffusion of solid brazed metal in liquid BFM; $J_{\text {diff }}^{\mathrm{BFM}}$ — diffusion of liquid BFM in solid brazed metal; $B_{m} C_{k}$ - seam; $\mathrm{Me}_{n} C_{k}$ - intermetallic interlayer

insignificant or completely absent, and level of their chemical affinity is high.

Interaction of brazed metal with liquid BFM (after wetting is finished) can promote at the interface two mutually opposite processes, namely dissolution of solid metal in liquid one, and diffusion of atoms of liquid metal in solid one (Figure 1).

Formation of the intermetallic interlayer at brazed metal-liquid BFM interface is possible:

- as a result of chemical reaction between brazed metal and liquid BFM under condition that the rate of intermetallic growth is higher than the rate of its dissolving in the seam; i.e. $v_{\mathrm{gr}}>v_{\text {dissol }}$;

- as a result of liquid BFM saturation with atoms of brazed metal along the interface.

As it is shown in work [5], growth of intermetallic in contact of solid, more refractory metal, and liquid, more fusible metal, in the first approximation obeys the law:

$$
\Delta^{2}=C\left(t-t_{0}\right)
$$

where $C$ is the concentration; $t, t_{0}$ are the time.

It follows from this that growth of the intermetallic is possible to the side of liquid phase, or to the side of solid metal. The rate of this process is determined by a rate of transfer of atom of solid metal in a near-boundary layer of liquid one, or by a rate of diffusion of dissolved atoms from a near-boundary layer in the seam. This dependence has parabolic nature typical for thermal-chemical processes. For the first time it was experimentally determined by G. Tamman. and then theoretically obtained by K. Wagner [6]. Formed continuous layer of solid product move away the reacting substances from each other, therefore rate of their diffusion delivery through the thickness of the intermetallic layer becomes the main factor, determining general rate of reaction [7].

Study of the process of intermetallic growth in liquid BFM-brazed metal system requires consideration of solubility of the reaction products. In liquid phase, if liquid is not saturated with a component of solid brazed metal, then its dissolving takes place simultaneously with intermetallic growth. Therefore, general change of layer thickness can be determined from a difference of dissolution and growth rates.

Rate of dissolution of layer of intermetallic is described by equation [8]

$$
\begin{gathered}
\frac{d x}{d t_{\text {dissol }}}=b \exp (-a t) ; \\
a=K(S / V) ; \quad C_{\mathrm{s}} K / \rho_{\mathrm{int}} \varphi,
\end{gathered}
$$

where $K$ is the constant of dissolution rate; $C_{\mathrm{s}}$ is the concentration of elements saturation in intermetallic; $\rho_{\text {int }}$ is the density; $\varphi$ is the content of elements in intermetallic; $t$ is the time of dissolution of brazed metal in BFM.

Due to the fact that brazing process is characterized by limited volume of the liquid BFM in a gap, the constant of dissolution rate can be found using Berthoud equation [6]:

$$
\left.\ln C_{\mathrm{s}}^{0} / C_{\mathrm{s}}^{0}-C^{0}\right)=K(S / V) t
$$

This equation describes the case of dissolution of semiinfinite solid, being in contact with area $S$ and volume $V$ of the liquid BFM in a brazing gap.

Growth rate is expressed as

$$
\frac{d x}{d t_{\mathrm{gr}}}=\frac{K_{0}}{1+\frac{K_{0} x}{K_{1}}},
$$

where $K_{0}$ is the chemical constant of diffusion; $K_{1}$ is the physical constant of diffusion.

In this connection one of the problems of current investigation was to study the ways for delaying the growth of intermetallic interlayer due to emission of elements promoting their dissolution in the seam.

Interface interaction of iron with liquid $\mathrm{Cu}-\mathrm{P}$ BFM usually provides for formation of the layers of higher phosphides, promoting embrittlement of the brazed joints.

Examination of phase and chemical composition of the interaction zone with the help of X-ray analysis showed that it consists of $\mathrm{Fe}_{2} \mathrm{P}$ and $\mathrm{FeP}$ phosphides (Figure 2), thermodynamic possibility of formation of which is verified by calculation of Gibbs potential of corresponding reactions [9], re-calculation of which on equilibrium constant showed that it is more than one in all cases:

$\mathrm{Cu}_{3} \mathrm{P}+2 \mathrm{Fe}=3 \mathrm{Cu}+\mathrm{Fe}_{2} \mathrm{P}, \quad \Delta \mathrm{G}_{298}=-40.74 \mathrm{~J} / \mathrm{mole} ;$

$\mathrm{Cu}_{3} \mathrm{P}+\mathrm{Fe}_{2} \mathrm{P}=2 \mathrm{FeP}+3 \mathrm{Cu}, \Delta \mathrm{G}_{298}=-11.3 \mathrm{~J} / \mathrm{mole}$.

It means that formation of reaction products in a form of iron phosphides is inevitable at presence in a reaction zone of the initial substances and at continuous removal of the reaction products from the zone. Their microhardness makes HV20-820-960 MPa, 
thickness of brittle interlayer depending on brazing mode and content of phosphorus in the BFM can reach $40 \mu \mathrm{m}$.

Constitutional diagram of $\mathrm{Fe}-\mathrm{Cu}-\mathrm{P}$ system, which is drawn based on results of thermal and microstructure investigations, show that formation of mixed crystals (solutions) were not observed at 2.5 wt.\% of $\mathrm{Fe}_{2} \mathrm{P}$, since even two alloys with 1 wt. $\%$ of $\mathrm{Fe}_{2} \mathrm{P}$ and 1 wt. $\%$ of $\mathrm{Cu}_{3} \mathrm{P}$ remained two-phase after twohour annealing below eutectic temperature (Figure 3 ). Wetting by $\mathrm{Cu}-\mathrm{P}$-based BFM and simultaneous elimination of possibility of iron phosphide formation at the fusion line requires selection of such an alloying element, which would promote for mutual dissolution between $\mathrm{Fe}_{2} \mathrm{P}$ and $\mathrm{Cu}_{3} \mathrm{P}$ and between iron and copper. In this connection, effect of alloying elements $\mathrm{Me}$ (where $\mathrm{Me}$ is $\mathrm{Zn}, \mathrm{Mn}, \mathrm{Cd}, \mathrm{Bi}, \mathrm{Pb}, \mathrm{Al}, \mathrm{Ni}, \mathrm{Sn}, \mathrm{Ti}, \mathrm{In}$ ) on phase composition of quasi-triple $\mathrm{Cu}_{3} \mathrm{P}-\mathrm{Fe}_{2} \mathrm{P}-\mathrm{Me}$ system is considered.

Thermal-dynamic evaluation showed the possibility of reaction of copper phosphide with titanium at titanium introduction in $\mathrm{Cu}-\mathrm{P}$ alloy:

$$
\mathrm{Cu}_{3} \mathrm{P}+3 \mathrm{Ti}=\mathrm{Ti}_{3} \mathrm{P}+3 \mathrm{Cu} \text {. }
$$

Formed titanium phosphide $\mathrm{Ti}_{3} \mathrm{P}$, having hexagonal lattice similar to copper phosphides $\mathrm{Cu}_{3} \mathrm{P}$, can form $(\mathrm{Cu}, \mathrm{Ti})_{3} \mathrm{P}$ solid solution. This solid solution prevents interaction of iron with phosphorus in brazing and eliminates formation of $\mathrm{Fe}_{2} \mathrm{P}$ interlayer.

Increase of titanium content to 0.9 atomic fractions revealed the copper lines on $\mathrm{X}$-ray pattern. This indicates $\mathrm{Cu}_{3} \mathrm{P}$ reduction to metallic copper with formation of titanium phosphides.

Introduction of manganese in $\mathrm{Cu}-7 \% \mathrm{P}$ alloy provides for a thermodynamic probability of formation of manganese phosphides $\mathrm{Mn}_{3} \mathrm{P}$ by reaction

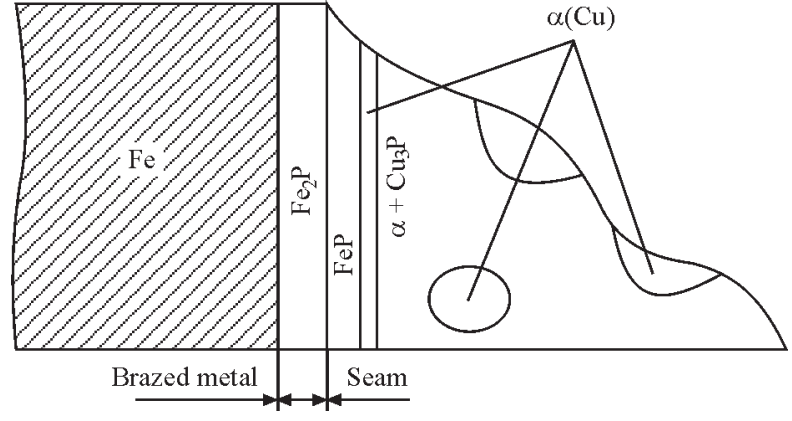

Figure 2. Scheme of formation of intermetallics in iron brazing using $\mathrm{Cu}-\mathrm{P}$ BFM

$$
\mathrm{Cu}_{3} \mathrm{P}+3 \mathrm{Mn}=\mathrm{Mn}_{3} \mathrm{P}+3 \mathrm{Cu} .
$$

According to reference data [8] the alloy forms a triple phase with hexagonal lattice similar to $\mathrm{Fe}_{2} \mathrm{P}$ at $0.25 \mathrm{~mol}$ \% Mn. Composition of the phase is not determined but, at the same time, phosphorus in these compounds is in bound state and eliminates its combination in brazing with iron with intermetallic formation.

The specimens of quasi-triple $\mathrm{Cu}_{3} \mathrm{P}-\mathrm{Fe}_{2} \mathrm{P}-\mathrm{Me}$ system contain the phases, which are present in quasi-binary sections $-\mathrm{Fe}_{2} \mathrm{P}-\mathrm{Mn}$ and $\mathrm{Cu}_{3} \mathrm{P}-\mathrm{Mn}$, limiting this system.

Nickel and its phosphides can form the continuous solid solutions with iron as well as copper [10]. Similarity of the crystalline lattices of copper solution and iron phosphides and their parameters indicate that introduction of nickel in the $\mathrm{Cu}-\mathrm{P}$ BFM in brazing will promote their dissolution in the seam.

Therefore, according to Kurnakov rule [11], a solid solution between the compounds is better on properties than the properties of the separate compounds.

30 alloys of a wide range of concentrations were examined in tetradic system $\mathrm{Fe}-\mathrm{Ni}-\mathrm{Cu}-\mathrm{P}$ on $\mathrm{Fe}_{2} \mathrm{P}-$ $\mathrm{Cu}_{3} \mathrm{P}-\mathrm{Ni}$ section.
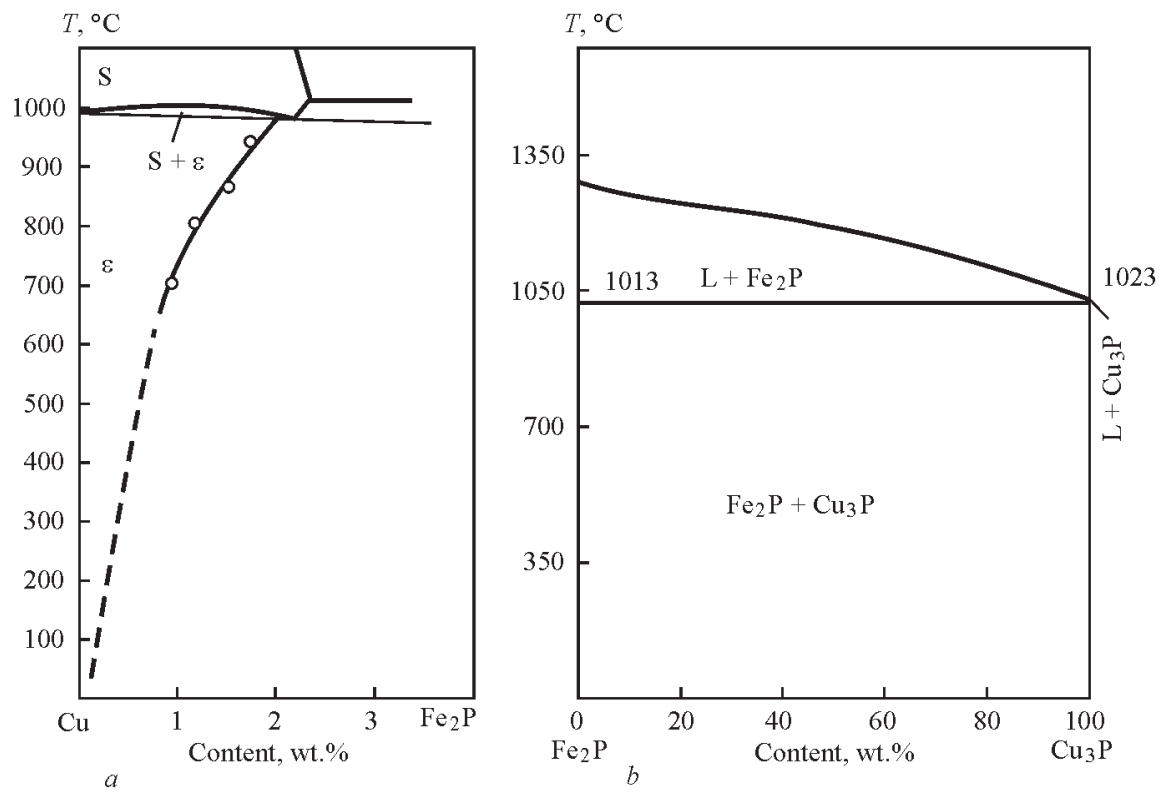

Figure 3. Quasi-binary section $\mathrm{Fe}_{2} \mathrm{P}-\mathrm{Cu}(a)$ and $\mathrm{Fe}_{2} \mathrm{P}-\mathrm{Cu}_{3} \mathrm{P}(b)$ of $\mathrm{Fe}-\mathrm{Cu}-\mathrm{P}$ system [8] 
In addition to earlier indicated phases of continuous series of solid solutions $(\mathrm{Cu}, \mathrm{Ni}),(\mathrm{Fe}, \mathrm{Ni})_{3} \mathrm{P}$, (Fe, $\mathrm{Ni})_{2} \mathrm{P}, \mathrm{FeP}$, a new phase (A) was discovered. It is received in the purest form at $\left(\mathrm{Fe}_{2} \mathrm{P}\right)_{0.6}\left(\mathrm{Cu}_{3} \mathrm{P}\right)_{0.2} \mathrm{Ni}_{0.2}$ composition, i.e. $\mathrm{Fe}_{1.2} \mathrm{Ni}_{0.2} \mathrm{Cu}_{0.6} \mathrm{P}_{0.8}$. Phase $\mathrm{A}$ is in equilibrium with continuous series of solid solutions $(\mathrm{Cu}$, $\mathrm{Ni}$ ) and $(\mathrm{Fe}, \mathrm{Ni})_{3} \mathrm{P}$, its $\mathrm{X}$-ray pattern is similar to the $\mathrm{X}$-ray pattern of $\mathrm{Co}_{2} \mathrm{P}$ phosphides having anti- $\mathrm{PbCl}_{2}$ structure type.

The specimen with phase A has less content of phosphorus than in phosphides with anti- $\mathrm{PbCl}_{2}$ structure. Therefore, 15 additional specimens of ( $\mathrm{Fe}, \mathrm{Ni}$, $\mathrm{Cu})_{2} \mathrm{P}$ composition with different ratio of atoms of metal and adjacent to them $\mathrm{Fe}_{4} \mathrm{Cu}_{2} \mathrm{P}_{3}$ specimen were manufactured. Manufacture of the latter was necessary in order to prove that phase A is a four-component compound and it is not a triple phosphide of $\mathrm{Fe}-\mathrm{Cu}-\mathrm{P}$ system. The phase analysis of all additional specimens verified that phase $\mathrm{A}$ is a tetradic phosphide of alternating composition $\mathrm{Fe}_{1.3-1.6} \mathrm{Ni}_{0.2} \mathrm{Cu}_{0.5-0.2} \mathrm{P}$ forming only after annealing at $870 \mathrm{~K}$.

Formation of the tetradic compound $(\mathrm{Fe}, \mathrm{Ni}, \mathrm{Cu})_{2} \mathrm{P}$ with anti- $\mathrm{PbCl}_{2}$ structure type indicate that its morphotropic transfer is related with change of electron concentration.

Carried analysis show that introduction of $\mathrm{Mn}, \mathrm{Ti}$ or $\mathrm{Ni}$ in the $\mathrm{Cu}-\mathrm{P}$ BFM improves the seam quality in brazing of Fe-based alloys. $\mathrm{Fe}_{1.3-1.6} \mathrm{Ni}_{0.2} \mathrm{Cu}_{0.5-0.2} \mathrm{P}$ phosphide, forming after annealing and having rhombic structure of anti- $\mathrm{PbCl}_{2}$ type, was found in the quasi-triple system $\mathrm{Cu}_{3} \mathrm{P}-\mathrm{Fe}_{2} \mathrm{P}-\mathrm{Ni}$.
From thermodynamic point of view, brazing process should be carried out at the lowest overheating and the minimum time of contact with the brazed metal. The brazing temperature should be lower and the rate of heating when reaching operating temperature the largest.

1. Mars, O., Srtoizcek, M., Persson, U. (2012) Erosion control of stainless steel brazing alloys. In: Proc. of $5^{\text {th }}$ Int. Brazing and Soldering Conf. (Las Vegas, USA, April 22-25, 2012), 169-173.

2. Lashko, N.F., Lashko, S.V. (1977) Contact and metallurgical processes in brazing. Moscow: Metallurgiya.

3. Duffey, M.J., Marchal, J.T., Loney, M.R. et al. (2015) Strength of brazed joints and metallurgical testing of $\mathrm{Cu}-4 \mathrm{Sn}-6 \mathrm{P}$ and $\mathrm{Cu}-40 \mathrm{Zn}-1 \mathrm{Sn}-0,3 \mathrm{Si}$ silver-free filler metals. In: Proc. of Int. Brazing and Soldering Conf. (Long Beach, USA, April 19-22, 2015).

4. Li Yajiang, Wang Juan, Liu Kun et al. (2015) Microstructure and fracture morphology of Mo/CuCr18-Ni18 brazing joint with Ni-Cr-P filler metal. In: Ibid.

5. Nikitin, V.I. (1967) Physical-chemical phenomena under the impact of liquid metals on hard metals. Moscow: Atomizdat.

6. Dybkov, V.I. (2002) Solid phase chemical kinetics and reactive diffusion. Kiev: NANU.

7. Shatinsky, V.F., Zbozhnaya, O.M. (1976) Producing diffusion coatings in fusible metals medium. Kiev: Naukova Dumka.

8. (1986) Constitutional diagrams of binary and multicomponent systems on iron base: Refer. Book. Ed. by O.A. Bannykh. Moscow: Metallurgiya.

9. Chase, M.W. (1980) JANAF Thermochemical Tables. 3rd ed., 1856. Midland: Thermal Group.

10. Matyushenko, N.N. (1969) Crystalline structures of binary compounds: Refer. Book. Moscow: Metallurgiya.

11. Kornilov, I.I. (1964) Metallides and their interaction. Moscow: Nauka. 